\title{
- INFRASTRUCTURE DISRUPTION IN 'SILICON SAVANNAH': Exploring the Idea of the Creative Class and their Relation to Quality of Place in Nairobi, Kenya
}

\author{
LAUREN ROSENBERG AND ALAN BRENT
}

\begin{abstract}
Debates around urbanization, infrastructure disruption and the creative class rarely appear alongside each other in research on African cities. This article connects these different narratives, which are currently exerting their influence on the future direction of these cities. The economic value of the creative class is that their work centres on innovation-a quality seen as essential to 'new-economy' urban growth. Quality of place (that which makes 'New York New York') is said to attract the creative class to certain cities, as lifestyle amenities are valued as much as employment opportunities. Nairobi is an example of an African city currently attracting both Kenyan and expatriate creative class workers, particularly in the information and communication technology (ICT) sector. In this article we take Richard Florida's creative class theory as a departure point to offer insights into why this group chooses to live in Nairobi and to describe Nairobi's quality of place, with a particular focus on infrastructure disruption. The case study reveals that Nairobi's quality of place differs fundamentally from the normative attributes prescribed by creative class theory and, in some instances, it is considered to be highly frustrating and unattractive.
\end{abstract}

Lauren: You said you 'liked it here, so you stayed'; could you unpack that a bit more? What exactly do you like about it?

Tim: Um, yeah, to be honest not the city that much; it's very hard to get around, you get heckled a lot as a mzungu [foreigner], you get cheated a lot, or people attempt to cheat you a lot, everywhere, riding matatus [minibus taxis], at the store, everywhere. So it's a bit of a pain living here. You have to take taxis everywhere at night because it's not entirely safe, ah, things like that, but the tech scene here is just amazing .... and the entrepreneurs here-both Kenyan and expats-are all really interesting, really cool people.

\section{Introduction}

East Africa is the least urbanized region on the African continent, and its economic hub is undoubtedly Nairobi, Kenya (UN-HABITAT, 2010; Dill and Crow, 2014). Established as a transportation centre by British colonial rulers in 1899, Nairobi today is the regional hub for transport, commerce, tourism, trade and conferences (Owuor and Mbatia, 2012). Nairobi is a 'new city' in some regards: it is one of the youngest cities in the East African region and projected to be one of the fastest-growing and largest cities in Africa (UN-HABITAT, 2010; 2014; Myers, 2015). Between four and five million people live in Nairobi, and over $60 \%$ of the city's inhabitants are living in slums (Thieme, 2015). Recently, Nairobi has been dubbed 'Silicon Savannah' - a reference to Silicon Valley-because of the boom in technology innovation occurring in the city (Manson, 2011; The Economist, 2012; Graham and Mann, 2013). This emergent trend can mainly be attributed to the implementation of a state development blueprint called Vision 2030. Vision 2030 aims to develop Kenya's economy through ICTs, with a dual emphasis on providing better infrastructure for ICT services, and on building a state-of-the-art ICT park called Konza Technology City, which will provide Business Process Outsourcing (BPO) to foreign companies (Adeya and Munywoki, 2012). 
Currently, Kenya rates higher than the global index average in terms of ICT and technology entrepreneurship (it is second only to Nigeria on the African continent): 'in the span of two to three years ... the innovation scene in Kenya has greatly expanded ... At the front line, pushing for this progress has been the Kenya ICT Board' (Moraa and Mwangi, 2012: 4). ${ }^{1}$ The technology and innovation scene in Nairobi, in particular, has become very attractive, and there is a significant clustering of the creative class (to use Richard Florida's phrase) in the city. These workers include both Kenyans (many of whom have studied abroad for several years) and foreigners who believe they can 'make it' in the city (Kalan, 2011).

Florida (2005) argues that the creative classes tend to cluster in certain cities over others and that quality of place is central to this phenomenon. ${ }^{2}$ Quality of place is a heuristic signifier of the various inherited, acquired and built-up characteristics of places (Arora et al., 2000). Without high quality-of-place attributes, Florida argues, cities are doomed to economic stagnation. In brief, the creative class work in a 'no-collar' workplace, enjoy an 'experiential lifestyle' characterized by a 'time warp', where time spent on work and play are blurred into one (Florida, 2004). Typical quality-of-place attributes that Florida claims the creative class find attractive include: easy access to a wide range of outdoor activities; a clean, healthy environment and a commitment to preserving natural resources for enjoyment and recreation; a wide range of nightlife experiences (including many options without alcohol); a lifestyle that is youth-friendly and supportive of diversity; and a vibrant music and performance scene with a wide choice of live-music opportunities (Florida, 2005). Clearly, Florida's data, observations and expectations derive from the United States. Therefore one might expect cultural and economic differences, although the cheerleaders of the creative class seldom acknowledge it. Our aim in this article is not to prove or disprove Florida's theorysufficient debate exists already (see Peck, 2005; Wilson and Keil, 2008; Darchen and Tremblay, 2010; Krätke, 2010; Martin-Brelot et al., 2010; Pratt, 2011). Rather, we argue that Florida's normative creative city is an inappropriate mould for describing the urbanism that is attracting the 'creative class' to Nairobi. Exploring notions of quality of place within an African city context provokes and demands a more nuanced view of 'the creative city', as this context is empirically divergent from the urban landscapes imagined by both Florida and (to a certain extent) his critics.

The creative class theory assumes that urban infrastructure is 'always on'. Beyond brief references to mobility infrastructure, disruptions to urban infrastructure supply are barely considered in creative class literature, despite the intimate connection between physical infrastructure networks and everyday life (Guy and Marvin, 2001). The baseline reference point of this literature is the Western city, where infrastructural services are 'virtually ubiquitous and utterly ordinary' (Graham, 2010: 6). This can be mainly attributed to the urbanization patterns that cities in the global North have followed: an urbanism of economic growth through industrialization, with concomitant investments in infrastructure. In comparison, African cities exist today because of vastly different mechanisms of urbanization. Assuming that urban infrastructure (and ICTs and electricity in particular) are uninterrupted and 'always on' is simply inappropriate for most of urban(izing) Africa. For example, less than 5\% of Lagosian households have access to formalized electricity connections (McFarlane, 2010). If African cities are attracting members of the creative class, what do we make of Florida's 'quality of place' proposition in light of the fact that these cities do not look and feel as Florida prescribes they should? The point here is not to draw a modernist comparison; instead, we argue

1 For example, the Kenya ICT Board played a critical role in securing the SEACOM and East African Marine Systems undersea optical-fibre internet cables in 2009 (Waema et al., 2010).

2 Florida's core thesis centres on economic growth opportunities for cities that excel in the ' 3 Ts': talent, technology and tolerance. Florida describes quality of place as the fourth $\mathrm{T}$ (territorial assets). This article does not address issues of tolerance in Nairobi, nor is it a quantitative assessment of talent and technology in Nairobi. 
that notions of quality of place for the creative class are incomplete when we consider the rise of technological innovation in African cities. African cities have not featured in the creative class literature; yet it is possible to include Cape Town, Kigali, Nairobi, Johannesburg, Cairo, Accra and Lagos as evidence of economic development through a form of creative class entrepreneurship, particularly in the technology sector. ${ }^{3}$ This trend is not easily found in academic literature, but can be located in abundance in 'grey literature' and social media. For example, the many business incubators and co-working spaces (often referred to as hubs) that have sprung up across the continent in different cities (Moraa and Gathege, 2011; Mutua, 2012) ${ }^{4}$ strongly suggest that there is a vibrant urban African tech scene, albeit one that takes on different forms to popular models such as those of the US and Europe.

American and European technology entrepreneurs are moving to Nairobi to start long-term businesses. This is a different trend from the usual high turnover of United Nations and other aid workers for which the city is known. Two of the United Nations' largest departments have their headquarters in Nairobi, and many other foreign aid organizations choose Nairobi as their African or regional headquarters. Some entrepreneurs have argued that the sheer density of aid workers in the city creates a false economy, as economic gains that could accrue to local workers are diverted out of the local economy. ${ }^{5}$ Current urbanization trends place Nairobi in a very different category to cities that are typically considered in creative class literature (for example, Amsterdam or San Francisco) where urbanization is largely complete. More generally, academic literature has been slow to track ICT use related to economic development in urban contexts in the global South, focusing rather on rural ICT4D projects. ${ }^{6}$ This is peculiar when compared to the dominant bias of past investments into the ICT sector in Africa, which tended to focus on urban areas instead (Briceño-Garmendia and Foster, 2010). The research that does exist on ICT diffusion in urban Africa tends to analyse applications of ICT to small- and medium-sized enterprises or cyber/internet cafés. ${ }^{7}$ The same lack of focus applies to the case of Nairobi. While online news media and blogs have eagerly documented the growth of the technology scene, academic literature seems to have barely taken notice beyond recognizing the mobile money revolution launched by M-Pesa-a mobile-phone-based finance service developed by dominant mobile network operators-in 2007.

Attention to contextual dynamics is needed to better recalibrate perceptions so that we can properly (re-)describe what is happening in Nairobi. The dynamics of a city are constituted by 'complex mixes of flows that cannot be predicted with any precision prior to the actual experience (and analysis) of the context' (Swilling and Annecke, 2012: 110). We aim to unpack part of the 'mix of flows' that creative class workers in Nairobi experience as a means of exploring quality of place in context.

\section{Research methodology}

Data was collected through 16 semi-structured interviews conducted in Nairobi in July 2012 after an initial period of context observation in March 2012. ${ }^{8}$ Sampling was achieved through both purposive pre-selection and snowballing techniques. Two

3 Meagher (2013) has tenuously explored some tenets of the creative class theory in the context of current city planning in Kigali.

See also https://africahubs.crowdmap.com/ (accessed 6 February 2020).

See, for example, Hersman (2011).

ICT4D was born in the 1990 s in response to general availability of the internet and the introduction of the Millennium Development Goals (Heeks, 2009). The archetypal manifestation of ICT4D is the rural telecentre (Heeks, 2009; Toyama, 2010); however, this has changed greatly since mobile phones have become ubiquitous, leading to innovation as a result of this diffusion.

7 See, for example, Falch (2004), Mwesige (2004), Hassanin (2009), Molony (2009), Yitamben and Tchinda (2009) and Wyche et al. (2010).

8 The study utilized an idiographic inductive case-study approach. Inductive case studies are typically highly descriptive, and data analysis is not constrained by a theoretical framework (Levy, 2008). 
criteria were used: interviewees needed to be working in an ICT-related field, and they needed to be living in Nairobi on a medium- to long-term basis (longer than a year). ${ }^{9}$ Interviewees were asked to draw maps during these interviews to elaborate on qualityof-place features, as well as supply a word or phrase that they thought encapsulated Nairobi to them. These were done at the end of the interview on a blank page. Subjects found the mapping somewhat daunting and some were slightly apprehensive before beginning to draw..$^{10}$ The aim of this was to encourage spatial thinking about place in a creative manner that broke away from the traditional interview format. Additionally, a much bigger group of roughly 40 individuals was sampled using a large map of the city for similar purposes at Nairobi's Innovation $\mathrm{Hub}$ (iHub), 'the nerve center for all things tech in Kenya' (Hersman, 2012: 61). The iHub was specifically chosen for the group mapping exercise because it is known for the large variety of ICT and creative class workers that it attracts (Hersman, 2012; Graham and Mann, 2013). Individuals were invited to indicate where in the city they lived ('home'), where they worked ('work'), and where they had fun or went to find inspiration ('fun'/'inspiration'). ${ }^{11}$ It is worth bearing in mind that Nairobi is an unequal, stratified city with a high Gini-coefficient, something that is clearly visible when spending any amount of time in the city (Myers, 2015). ${ }^{12}$ Therefore, the quality of place explored here applies to a very small fraction of the population, all of whom are relatively affluent. It is thus impossible to make general inferences about the locational choices of the creative class in Nairobi beyond the case sample.

\section{Hanging out: 'local bars' and shopping malls}

What is it that creative class workers in Nairobi enjoy doing? Our inquiry focused on the places in the city that respondents referred to as hangout spots or places of inspiration, as well as on sites that individuals deemed as important places that they frequented. It also reflected on an average spread of amenities and activities (shopping malls, bars and some parks) typical to many cities. Unique characteristics included nyama chomas (restaurants where barbequed/flame-grilled meat is served) and on what expatriates call 'local bars' that serve traditional Kenyan food and play Kenyan music. Small side-of-the-road lunch booths (kibandas) near working spaces were also frequented during the lunch hour.

Our research findings show a clustering of offices, residential locations and entertainment and leisure venues away from the central business district (CBD) in a westerly direction along Ngong Road. In general, shopping malls across the city were also popular destinations. Some respondents commented that entertainment options not involving alcohol were limited. Others expressed their happiness at the growing cultural scene and increasingly participated in cultural events instead of the custom of getting drinks at a bar: 'artists and musicians and poets are doing things and they're kind of on your level ... it's becoming really compelling, culturally' (John). One respondent, however, commented that many of the emerging new cultural and artistic activities in the city were fast becoming 'mainstream'.

There was no clear consensus on perceptions of the CBD: some enjoyed its diversity and vibrancy, while others felt it was too crowded and too unsafe. A few respondents noted that their favourite cultural hangout spots were in the CBD. ${ }^{13}$ Apart

9 The aim of sampling in an idiographic case study, especially where the sample involves entrepreneurs, is not to present 'success stories', nor is it to provide a representative sample of a region, but rather to access a sample that has a manageable size and is rich in detail (Berglund, 2007).

10 Gibson et al. (2012) note a similar response in their study, although printed city maps were used instead of blank pages.

11 Given the focus on the intrinsic worth of context, Lauren Rosenberg purposefully visited and experienced places that interviewees regarded as important to their sense of place.

12 The city has a Gini coefficient (income-based) of 0.59 (UN-HABITAT, 2008).

13 These include a campus of the University of Nairobi, a Goethe Institute, a chapter of the Alliance Française and a multidisciplinary arts space named the GoDown Arts Centre. 
from what was observed at co-working spaces and cultural hubs, there appeared to be little in the way of an 'experiential lifestyle' (Florida, 2004). One respondent, a newcomer to the city, complained that lifestyle options were limited to 'little gated communities and gated shopping centres' (Dale). Only a few respondents made direct reference to social inequality in Nairobi as a function of quality of place, noting the politics of propinquity in the city (Amin and Thrift, 2004). One commented that 'Nairobi is like filled with these pockets of like, "bougey" [bourgeois] upper-class areas and right behind them is always a slum or a lower-class settlement, where everyone who supports that system works' (Mandini).

Several individuals found it hard to relax in Nairobi-there was a sense that the city was too fast-paced and stressful, and that it was difficult to find calm and peace on a regular basis. Others believed that this was directly linked to a lack of natural beauty and environs to enjoy within the city boundaries. It seemed to various respondents that to feel truly relaxed in Nairobi, you needed to leave the city. Nairobi's quality of place is enhanced by its close proximity to many attractive tourist locations that are easily accessible for weekend trips. Respondents enjoyed being able to 'go off and hang out in the Maasai Mara for a weekend' or to 'take a game drive four hours that way towards Mombasa into Savo ... in an environment where you don't even have mobile phone reception'. Others mentioned visiting family members who lived in nearby counties to relax in a rural setting. Overall, it seemed that those who frequently left the city to visit nearby tourist attractions were either expatriates or well-established entrepreneurs.

\section{Infrastructure disruption in 'Silicon Savannah'}

In Nairobi, infrastructure disruption must be considered as an authentic qualityof-place attribute. Scheduled and unscheduled electricity disruptions (blackouts) are frequent in Nairobi. ${ }^{14}$ All interviewees commented on electricity outages as a quality-ofplace attribute, and this was also evident from several power cuts we experienced at our interview venues. However, in most cases a generator would kick in within less than a minute, and machines, lights and water coolers would be humming again. Interestingly, electricity disruptions did not seem to be an insurmountable challenge to the flow of business, and although ICTs are disrupted when the power goes out, 3G internet access (via mobile phones or USB modems) usually bridges the gap until power is restored. The two dominant areas of infrastructure disruption that emerged were mobility constraints and unreliable water supply-perhaps not the first concerns one might expect in the 'creative city':

you're not just like walking on the street and like dipping into a coffee shop or walking down the street and 'oh I'm going to go shopping there'. It's like you have to plan and I'm going to there, and that's where I'm going to get in my taxi and then go there (Dale).

Mobility infrastructure within African cities is a highly important feature of place; it is the point at which the private car-a quintessential signifier of modernity in developing countries-and the colonially configured road space converge (Robinson, 2006; Graham and Thrift, 2007; Pieterse, 2008; Manji, 2015). In Nairobi, this manifests itself in the colossal traffic jams, its potholed roads and the heavy air pollution. Mobility in Nairobi has been a policy concern for several years (Omwenga, 2008; Klopp, 2012; Salon and Aligula, 2012; Ogendi et al., 2013), and although public transport is extensive, covering all areas of the city, often the experience of using it is somewhat unpleasant (Wa Mungai and Samper, 2006). 
We intentionally began our interrogation of Nairobi's quality of place with the subject of mobility, as this heavily influences an individual's sense of place. Hassle-free mobility is key to life in the creative city-the ability to move between different scenes, spaces and places on a just-in-time basis, or to relax cycling (Florida, 2005). Nairobi was recently found to have the world's fourth most painful commute (IBM, 2011), ${ }^{15}$ with air pollution at $550 \%$ over the US legal limit (Sclar and Touber, 2008). ${ }^{16}$ Its infrastructure is not cyclist-friendly. Unsurprisingly, respondents commented extensively on traffic congestion within the city-a frustrating, often infuriating, attribute of place that is inseparable from an individual's perception of Nairobi. For example, conducting business is testing when meetings take place on the other side of town, which is not geographically far (usually between seven and 15 kilometres) but can seem a world away when traffic is taken into account. In a much larger sample of 2,105 households (representing close to 7,500 individuals), Salon and Aligula (2012) show that across different modes of transport (including walking) most trips taken in Nairobi are less than five kilometres. Overall, both the Kenyan and expatriate respondents we interviewed faced mobility frustrations associated with the state of the roads (potholes, drainage and lack of clean pedestrian walkways) and with safety and security issues related to mobility. Three quarters of our respondents referred to crime or to feeling insecure (often as a function of mobility decisions) as characteristic of Nairobi's quality of place.

Another interesting example of how mobility frustration is a function of Nairobi's quality of place was revealed in the map that respondents drew. Although one respondent noted that lack of maintenance of roads in Nairobi was frustrating, explicit references to traffic as a key attribute of place came out strongly during the drawing of the city maps. Respondents radically highlighted congestion and complex commute routes, stressing the difficulty of the coexistence of pedestrians and private vehicles on the roads. In an attempt to understand Nairobi's genius loci, as many forms of available transport as possible were explored to enrich the information respondents provided in the interviews: matatus (minibus taxis), private taxicabs, buses, boda bodas (motorcycle taxis) and walking, especially during peak hour traffic. ${ }^{17}$ From first-hand experience, we can confirm that it is easy to relate to the sentiment that mobility is 'the biggest pain ... day to day, it's not that hard to get around, but it's not fun' (Tim). Existing research on mobility within Nairobi reveals an overwhelming reluctance of Nairobians to consider using bicycles to commute in the city, despite the mild climate and relatively flat topography, owing to safety concerns and to the absence of dedicated cycling paths (Salon and Aligula, 2012), although, despite the risk, some of the poorest residents of Nairobi would actually be willing to bicycle commute but could not afford bicycles. Klopp (2012:3) notes that the combination of urban dynamics and the high rate of urbanization in Nairobi makes 'daily routines and movement around the city stressful, unhealthy, expensive, and sometimes precarious’. For expatriates, specifically, mobility frustrations centred on the experience of sticking out from the crowd or being cheated on fares ('mzungu tax'), ${ }^{18}$ while Kenyans mainly complained about drivers' attitudes and their lack of respect for the rules of the road and for other road users:

I don't drive much but when I do, just driving in Nairobi it's ... it shortens your life (Atieno).

15 The survey sample included twenty cities: Bangalore, Beijing, Buenos Aires, Chicago, Johannesburg, London, Los Angeles, Madrid, Mexico City, Milan, Montreal, Moscow, Nairobi, New Delhi, New York City, Paris, Shenzhen, Singapore, Stockholm and Toronto. In first position for the world's most painful commute was Mexico City, followed by Shenzen and Beijing.

16 For an in-depth analysis of air pollution in Nairobi and the long-term health implications thereof for its citizens, see Kinney et al. (2011).

17 For example: 'Actually, I'd rather walk from here to town because I'd take a shorter time. And now I see many people who do that, very many people, it's not because they're poor and can't afford transport, it's just that because of the time; they would rather walk' (James).

18 There is price discrimination between locals and foreigners (called mzungus in Kiswahili). 
Um, what also frustrates me is sticking out. I think like it sucks having people look at you all the time. Where it's like you're white, you look different (Gerri).

Also, individuals seemed to move to an area not because of its quality-of-place attributes (soft factors) but rather in response to a mobility infrastructure that would enhance their way of life and status; neighbourhoods with a shorter daily commute were deemed most attractive. A reliable water supply made a neighbourhood even more attractive:

\section{you have to look for other ways of getting water (Abasi).}

Connection to Nairobi's main water grid is not so much a problem as is a regular supply from the grid. The city of Nairobi in its entirety constitutes Nairobi County as a political and administrative unit and is the only county that is $100 \%$ urban in Kenya (Medard, 2010). In principle, Nairobi is relatively well-connected in terms of water infrastructure (compared to other urban counties) and has the largest number of formal connections per capita (World Bank, 2007). However, just under $76 \%$ of Nairobian households have access to the centralized water supply via piped connections (Kenya Open Data Initiative, 2012) ${ }^{19}$ Moreover, this figure does not reflect the means of water access of poorer households, nor the vast differences in cost of access and supply between neighbourhoods (Dill and Crow, 2014). ${ }^{20}$ Despite the relatively high level of connectivity to the centralized water supply, disruptions were very frequent, and private water vendors or other solutions such as boreholes often had to be sought. Disruptions to the water supply appeared to be neighbourhood-specific. In particular, it was possible for some to buy themselves out of the problem: 'if you want to live in a place where there's like water $24 / 7$... you have to pay quite an amount to live in a small apartment ... unless you live around maybe Statehouse-near the president [laughs]' (Faith). Finally, water quality is not optimal in Nairobi, and many households boil their water before consuming it.

\section{Here to stay: reflections on Nairobi's quality of place}

Even if it looks utterly chaotic and unplanned and so on, I get that sense of we're going somewhere, you know. People are not sitting some place at home defeated, it's people are scrambling to kind of just to get ahead you know where they are (John).

The findings from our research show that Nairobi's quality of place differs fundamentally from Florida's normative prescriptions. Partly this can simply be attributed to context: African cities differ profoundly from Western cities in myriad ways. Secondly, infrastructure disruption is a common feature of quality of place in African cities-something that is completely overlooked by Florida and even his fiercest critics. Over and above this, our research shows that despite Nairobi's frenzied character, the sample of creative class workers interviewed were not packing their bags to leave anytime soon. Their work is deeply rooted in the local context-clearly a factor that is more significant than the urban infrastructure disruptions around them, their fears about crime, or opportunities outside the country. While expatriates did note the rising cost of work permits as something that could possibly force them to leave Nairobi in future, this is not strictly a quality-of-life factor.

19 Kenya is the first sub-Saharan country and the second African country, after Morocco, to have an open government data portal.

20 For example, the Nairobi slum inventory (Pamoja Trust, 2008) provides excellent details of differences in cost for a 20-litre jerry can of water between slum communities. 
- $\quad$ 'The people' and leaving a legacy

The primary reasons respondents gave for staying in Nairobi can be broadly grouped into two categories. First, a very close attachment to people: friends and professional networks. Secondly, they mentioned the promise of leaving a legacy-of changing the city and indeed the country for better. Two examples out of the many given illustrate these points:

We don't have gold, we don't have oil, we don't have ... you know ... it's a country that's held together by the people, the sheer-to quote one of my favourite writers-'bloody-mindedness' of the people, it's just people are ... just don't give up (Atieno).

And then I applied to a better master's programme at Stanford, and again gotten in and had to turn that down, which was unfortunate because it was just, I couldn't walk away from this opportunity at that time, which was really tough, yeah (Mandini).

Others expressed interest in exploring business opportunities in other African citiesJuba, Kigali or Lagos-and some expressed an interest in the lifestyles they perceived Cape Town and Johannesburg to offer. One person mentioned that they would be interested in moving to New York City. However, although several expressed these sentiments and had a genuine interest for living abroad, it was quite clear that this was more out of curiosity for another context and not because of a desire to remove themselves from their current city in search of lifestyle opportunities offered by another city's quality of place (whether perceived or experienced).

Neither expatriates nor Kenyans who had studied and lived abroad expressed any interest in leaving Nairobi for the countries they had recently relocated from, although they referred to quality-of-place features that they missed from previous locations (bicycle trails, outdoor cafés, cheap classical concerts, and so on).

\section{Co-working spaces}

But generally, as long as I hang out in the iHub, I meet people, there's always people to be met, you know ... and of course there's the issue of electricity, of course the constant 'it's on it's off it's on it's off', but I think that being in the iHub has really helped, so I do most of my work from the iHub (Esther).

A significant feature of Nairobi's quality of place for respondents were co-working spaces and incubators. These locations function as spaces where creative class workers can also insulate themselves against infrastructure disruption, often at very low prices, or for free. Coffee shops in private malls are equipped with backup generators and wireless internet and, as in many other cities, draw creative class workers in. However, co-working spaces and incubators differ significantly from coffee shops in terms of the relatively lower cost of access as well as the nature of the type of space. Individuals consistently referred to 'the people' as being their favourite aspect of Nairobi, their source of inspiration in the city and their reason for remaining there. Spaces such as Nairobi's Innovation $\mathrm{Hub}$ (iHub) and business incubators (for example, $88 \mathrm{MpH}$ Garage Nairobi, NaiLab and MLab) not only offer the infrastructure and financial support, both of which most incubators in Nairobi offer new startups, but also invite and encourage collaboration among users through networking. The iHub is highly innovative in terms of infrastructure provision and has ensured constant internet access by arranging for one service provider's internet cables to terminate directly in the building and securing backup bandwidth supply with another provider in case of disruptions to the 
main undersea cables. Graham and Thrift (2007) note how disruptions to electricity infrastructure reveal what truly fuels the new economy: an 'electric-electronic nexus' that controls end users far more than they routinely acknowledge. The high levels of infrastructure disruption in Nairobi, coupled with the financial constraints that are characteristic of any startup venture, make co-working spaces very attractive. As startups grow, they might leave co-working spaces for bigger premises, where they have to take on the cost of infrastructure disruption insurance. One entrepreneur in a startup of more than twenty people working out of rented premises described that he had to pay US $\$ 4,000$ for an electricity inverter to counter power blackouts. However, the startup's internet was powered by the centralized main electricity grid, so 'if the main grid goes off we may still have power here but we don't have internet' (Hamadi) - highly debilitating for a business that depends entirely on the internet.

\section{Quality of place versus invincible infrastructure}

A discussion of infrastructure disruption and ICT creative class workers in Nairobi would be incomplete if it did not mention Konza Technology City, the prestigious ICT park megaproject planned by the Kenya ICT Board. Located some 60 kilometres outside Nairobi, Konza City is a greenfield development project offering 'one of the best locations to do business in Africa' (Adeya and Munywoki, 2012: 3). This statement reflects the investment opportunities it offers to foreign multinational companies for Business Process Outsourcing (BPO), lifestyle amenities (commercial offices, hospitals, shops and entertainment all within walking, cycling or Konza-provided public-transit access), and most notably, fool proof infrastructure supply (ibid.). The issue of its physical distance (and even greater temporal distance, owing to congestion) from Nairobi is to be resolved by a rail link service that will connect Konza to Nairobi CBD and the airport. Konza is therefore a 'turnkey' quasi-creative city. However, only one person in our survey indicated that they would be interested in moving their business operations to Konza City, but even so commented that the location of their target market would prevent them from doing so.

Given the close-knit and supportive nature of the technology community in Nairobi, many felt that moving to Konza City would either remove the benefits they were experiencing of being spatially close to the community, or that Konza would destroy the community itself:

When I look at the Konza City website and the plans and the 3D flyovers and so on, are they actually thinking in terms of community? ... Is someone actually thinking about the people who are moving there and the kinds of things that they need? And most of the talk is about, you know, the architecture and the infrastructure and the location (John).

Cause I think cities follow people, you know, or there has to be something that draws people, like-Konza, there's nothing really drawing us there; it's just structures (Esther).

They don't have who they'll put in Konza; you know there was a time when you wanted to bring HP, IBM, Oracle ... but those days are gone. The days where we used to talk about big outsourcing; those days are gone (Mbita).

When asked whether he would move to Konza City, one respondent was very clear on the issue: 'Hell no! And I told Dr. Ndemo the same'. Dr. Bitange Ndemo was the Permanent Secretary (PS) for the Ministry of Information and Communications from 2005 until 2013, and this statement implies a close, almost collegial, working relationship between the respondent and the PS. Several other interviewees noted their good working 
relationship with the PS too, or attributed the success of innovation in ICT in Kenya to Dr. Ndemo. ${ }^{21}$ Reports suggest that creative class ICT workers outside of the case sample are also sceptical about Konza City, and indicate that there is much discussion about how Konza will change, and possibly ruin, Nairobi's quality of place for creative class ICT workers (Akunga, 2012; Alliy, 2012; Saraswati, 2015). The quality of place of the city that attracts technology investors cannot, in fact, be found in the manicured and gated spaces of the quasi-creative city, as the marketing for Konza would lead one to believe. In fact, the city's talent resides and inhabits the organic networks that have formed in the city because of, and in spite of, continual infrastructure disruption. It is unsurprising that in trying to attract the creative class of Nairobi with optimal infrastructure configurations, Konza City simultaneously repels the very same group: 'old ideas can sometimes use new buildings, new ideas must use old buildings'. ${ }^{22}$

\section{Conclusion}

It's like those problems you learn to work around (Esther)

A recent assessment of the social, economic and environmental characteristics of 98 different cities across the world showed Nairobi to have below-average levels of liveability, as did Addis Ababa, Dar es Salaam, San Salvador and Abidjan (Liu et al., 2011). Richard Florida's creative class theory (even without the added consideration of urban infrastructure disruption) would suggest, at first glance, that a city such as Nairobi should not attract creative class talent-yet it continues to do so. Nairobi is simultaneously a city of opportunity (supplemented by highly supportive professional networks) and a city where infrastructure interruption restricts the very business opportunities offered by the city's growing new economy. There seems to be an accepted sense of living with constant infrastructure disruption: 'so we've learnt how to dance around all these frustrations' (Atieno). Apart from mobility issues, other infrastructure disruption has not been typically considered as a quality-of-place attribute in the literature. The question then is whether infrastructure disruption diminishes the experience of quality of place to the point where a city becomes unattractive to live in. In this article, we respond to this tension by prioritizing social and cultural context over 'best practice'. Moreover, we stress the need to look beyond the infrastructure at the people and practices that constitute the creative city.

Future research could further explore notions of quality of place in different African-city contexts where the creative class are flourishing despite what Florida or national planning policies contend. In this case study, only one individual, a Kenyan, had previously decided to leave Nairobi intentionally for rural Western Kenya for a period of more than a year, because she needed to 'get out of Nairobi and be in a serene place'. Some individuals also anticipated moving away from Nairobi in the future when their careers were more established, citing the hectic nature of city life and the city's traffic as reasons for relocating. It appears from this case study that, although creative class workers were repeatedly frustrated by infrastructure disruption, Nairobi remained an attractive city to live in, even if it meant taking regular breaks from it.

To conclude, instead of prescriptive standards for assessing quality of place, we might consider all cities 'ordinary'. An ordinary-city perspective starts with the assumption that 'all cities can be thought of as diverse and distinctive with the possibility

21 Hersman (2012), a pioneer in the Kenyan tech scene, has argued that innovation in the ICT sector would not have taken off as it has without the policy support of the PS and leaders of the Communications Commission of Kenya.

22 This piece of wisdom is from Jane Jacobs (1961: 188). Florida acknowledges that his work has been inspired by Jacobs, and indeed, others have noted this too. Darchen and Tremblay (2010: 226) note that 'it is important to mention that the point of view developed in the creative class thesis is not totally innovative' and that 'the creative class thesis is thus confirming, in a more assertive way, the previous works of other urban theorists'. 
to imagine (within the constraints of contestations and uneven power relations) their own futures and their own distinctive forms of cityness' (Robinson, 2006: 113). This notion gives us more room to refocus our attention on locational specificities and to move away from economic reductionism and discourses that urge cities to become 'world-class', 'global' or even 'creative' by implying a highly idealized form of urbanism with particular assumptions about infrastructure (Pieterse, 2008; Graham, 2010). Researchers who are interested in investigating the rise of the creative class in Africa may then explore the (locally defined) quality of place in new ways, drawing on a wide range of materials and experiences that are directly connected to the contexts in which such innovation is occurring. Those interested in the ICT sector are particularly encouraged to engage with actors in this industry. The emerging continental community is highly supportive of enquiry into their area of work and appears to be equally curious about research on issues of technological and urban change in their cities. Perhaps there are even lessons the North can learn from these experiences.

Lauren Rosenberg, Sustainable Development Programme, School of Public Leadership, University of Stellenbosch, Bellville Park Campus, Van der Horst Building, Carl Cronjé Drive, Bellville, 7530, South Africa, lauren@longmilescoffee.com

Alan Brent, Department of Industrial Engineering, School of Public Leadership, University of Stellenbosch, Bellville Park Campus, Van der Horst Building, Carl Cronjé Drive, Bellville, 7530, South Africa, acb@sun.ac.za

\section{References}

Adeya, C. and A. Munywoki (2012) Konza Techno City, Kenya: frequently asked questions [WWW document]. URL http://www.atpadvisory.com/pdfs/FAQs\%20 on\%20Konza\%20Techno\%20City.pdf (accessed 16 August 2012).

Akunga, C. (2012) The trouble with Konza [WWW document]. URL http://www.ihub.co.ke/blog/2012/09/the-troublewith-konza/ (accessed 28 September 2012).

Alliy, M. (2012) Africa's technology parks \& cities arms race-is it worth it? In W. Mutua and M. Alliy (eds.), Innovative Africa: the new face of Africa: essays on the rise of Africa's innovation age, Afrinnovator, Nairobi.

Amin, A. and N.Thrift (2004) The 'emancipatory' city? In L. Lees (ed.), The emancipatory city? Paradoxes and possibilities, SAGE, London.

Arora, A., R. Florida, G.J. Gates and M. Kamlet (2000) Human capital, quality of place, and location. H. John Heinz School of Public Policy, Carnegie Mellon University, Pittsburgh, PA.

Berglund, H. (2007) Researching entrepreneurship as lived experience. In H. Neergaard and J.P. Ulhøi (eds.), Handbook of qualitative research methods in entrepreneurship, Edward Elgar, Cheltenham and Northampton, MA.

Briceño-Garmendia, C. and V. Foster (2010) Africa's infrastructure: a time for transformation. World Bank, Washington, DC.

Darchen, S. and D-G. Tremblay (2010) What attracts and retains knowledge workers/students: the quality of place or career opportunities? The cases of Montreal and Ottawa. Cities 27.4, 225-33.

Dill, B. and B. Crow (2014) The colonial roots of inequality: access to water in urban East Africa. Water International 39.2, 187-200.

Falch, M. (2004) Tele-centres in Ghana. Telematics and Informatics 21.1, 103-14.

Florida, R. (2004) The rise of the creative class: and how it's transforming work, leisure, community and everyday life. Basic Books, New York, NY.

Florida, R. (2005) Cities and the creative class. Routledge, New York, NY.

Gibson, C., C. Brennan-Horley, B. Laurenson, N. Riggs, A. Warren, B. Gallan and H. Brown (2012) Cool places, creative places? Community perceptions of cultural vitality in the suburbs. International Journal of Cultural Studies 15.3, 287-302.

Graham, M. and L. Mann (2013) Imagining a Silicon Savannah? Technological and conceptual connectivity in Kenya's BPO and software development sectors. The Electronic Journal of Information Systems in Developing Countries 56.2, 1-19.

Graham, S. (2010) When infrastructures fail. In S. Graham (ed.), Disrupted cities: when infrastructure fails, Routledge, New York, NY.

Graham, S. and N. Thrift (2007) Out of order: understanding repair and maintenance. Theory, Culture \& Society 24.3, 1-25.

Guy, S. and S. Marvin (2001) Urban environmental flows: towards a new way of seeing. In S. Guy, S. Marvin and T. Moss (eds.), Urban infrastructure in transition: networks, building, plans, Earthscan, London.

Hassanin, L. (2009) Egyptian women artisans facing the demands of modern markets: caught between a rock and a hard place. In I. Buskens and A. Webb (eds.), African women \& ICTs: investigating technology, gender and empowerment, UNISA Press, Pretoria.

Heeks, R. (2009) The ICT4D 2.0 manifesto: where next for ICTs and international development? Working paper series, Development Informatics Group, Institute for Development Policy and Management, Manchester University, Manchester.

Hersman, E. (2011) The subtle condescension of 'ICT4D' [WWW document]. URL http://whiteafrican. com/2011/11/02/the-subtle-condescension-of-ict4d (accessed 20 November 2012).

Hersman, E. (2012) Mobilizing tech entrepreneurs in Africa. Innovations: Technology, Governance, Globalization 7.4, 59-67.

IBM (2011) Frustration rising: IBM 2011 commuter pain survey [WWW document]. URL http://www.profacility.be/piclib/ biblio/pdf_00000552UK.pdf (accessed 12 August 2012).

Jacobs, J. (1961) The death and life of great American cities. Penguin, Harmondsworth.

Kalan, J. (2011) Potential, poverty, politics \& parties: why Kenya attracts America's best \& brightest young social entrepreneurs. Huffington Post 20 September [WWW document]. URL http://www.huffingtonpost.com/ 
jonathan-kalan/potential-poverty-politic_b_969338. html (accessed 5 July 2012).

Kenya Open Data Initiative (2012) [WWW document]. URL http://www.opendata.go.ke/ (accessed 4 August 2012).

Kinney, P.L., M.G. Gichuru, N. Volavka-Close, N. Ngo, P.K. Ndiba, A. Law and E. Sclar (2011) Traffic impacts on $\mathrm{PM}(2.5)$ air quality in Nairobi, Kenya. Environmental Science \& Policy 14.4, 369-78.

Klopp, J.M. (2012) Towards a political economy of transportation policy and practice in Nairobi. Urban Forum 23.1, 1-21.

Krätke, S. (2010) 'Creative cities' and the rise of the dealer class: a critique of Richard Florida's approach to urban theory. International Journal of Urban and Regional Research 34.4, 835-53.

Levy, J.S. (2008) Case studies: types, designs, and logics of inference. Conflict Management and Peace Science 25.1, 1-18.

Liu, X., B. Derudder and Y. Liu (2011) Featured graphic: GDP, livability, population, and income inequality of world cities. Environment and Planning A: Economy and Space 43.10, 2255-56.

Manji, A. (2015) Bulldozers, homes and highways: Nairobi and the right to the city. Review of African Political Economy 42.144, 206-24.

Manson, K. (2011) Kenya's 'Silicon Savannah' to challenge India on IT. Financial Times [WWW document]. URL http://www.ft.com/cms/s/0/f99ee180-8d27-11e0815d-00144feab49a.html\#axzz3xgowLpKM (accessed 14 September 2012).

Martin-Brelot, H., M. Grossetti, D. Eckert, O. Gritsai and Z. Kovács (2010) The spatial mobility of the 'creative class': a European perspective. International Journal of Urban and Regional Research 34.4, 854-70.

McFarlane, C. (2010) Infrastructure, interruption, and inequality: urban life in the global South. In S. Graham (ed.), Disrupted cities: when infrastructure fails, Routledge, New York, NY.

Meagher, S.M. (2013) The darker underside of Scott's third wave. City 17.3, 395-98.

Medard, C. (2010) City planning in Nairobi: the stakes, the people, the sidetracking. In H. Charton-Bigot and D. Rodriguez-Torres (eds.), Nairobi today: the paradox of a fragmented city, Mkuki na Nyota and the French Institute for Research in Africa, Nairobi, Dar es Salaam.

Molony, T. (2009) Carving a niche: ICT, social capital, and trust in the shift from personal to impersonal trading in Tanzania. Information Technology for Development 15.4, 283-301.

Moraa, H. and D. Gathege (2013) How ICT hubs models have impacted on the technology entrepreneurship development. Proceedings of the Sixth International Conference on Information and Communications Technologies and Development, Cape Town, 7-10 December.

Moraa, H. and W. Mwangi (2012) The impact of ICT hubs on African entrepreneurs: a case study of iHub (Nairobi). iHub Research, Nairobi.

Mutua, W. (2012) Innovative Africa: the new face of Africa. In W. Mutua and M. Alliy (eds.), Innovative Africa: the new face of Africa: essays on the rise of Africa's innovation age, Afrinnovator, Nairobi.

Mwesige, P.G. (2004) Cyber elites: a survey of internet café users in Uganda. Telematics and Informatics 21.1, 83-101.

Myers, G. (2015) A world-class city-region? Envisioning the Nairobi of 2030. American Behavioral Scientist 59.3, 328-46.

Ogendi, J., W. Odero, W. Mitullah and M. Khayesi (2013) Pattern of pedestrian injuries in the city of Nairobi: implications for urban safety planning. Journal of Urban Health 90.5, 849-56.

Omwenga, M. (2008) Urban growth and sprawl-case study of Nairobi, Kenya. Paper presented at the network events at the World Urban Forum 4, Nanjing, China, 3-6 November.
Owuor, S. and T. Mbatia (2012) Nairobi. In S. Bekker and G. Therborn (eds.), Capital cities in Africa: power and powerlessness, HSRC, Cape Town.

Pamoja Trust (2008) An inventory of the slums in Nairobi. Pamoja Trust, Nairobi.

Peck, J. (2005) Struggling with the rise of the creative class. International Journal of Urban and Regional Research 29.4, 740-70.

Pieterse, E. (2008) City futures: confronting the crisis of urban development. UCT Press, Cape Town.

Pratt, A.C. (2011) The cultural contradictions of the creative city. City, Culture and Society 2.3, 123-30.

Robinson, J. (2006) Ordinary cities: between modernity and development. Questioning Cities series, Routledge, London and New York, NY.

Salon, D. and E. M. Aligula (2012) Urban travel in Nairobi, Kenya: analysis, insights, and opportunities. Journal of Transport Geography 22 (May), 65-76.

Saraswati, J. (2015) Konza City and the Kenyan software services strategy: the great leap backward? Review of African Political Economy 41, S128-37.

Sclar, E. and J. Touber (2008) Urban sustainability from theory to practice. Conference presentation, Center of Sustainable Urban Development, The Earth Institute, Columbia University, New York, NY.

Swilling, M. and E. Annecke (2012) Rethinking urbanism. In M. Swilling and E. Annecke (eds.), Just transitions: explorations of sustainability in an unfair world, Juta and Earthscan, Cape Town and London.

The Economist (2012) Upwardly mobile: Kenya's technology start-up scene is about to take off [WWW document]. URL https://www.economist.com/business/2012/08/25/ upwardly-mobile (accessed 6 February 2020).

Thieme, T. (2015) Turning hustlers into entrepreneurs, and social needs into market demands: corporatecommunity encounters in Nairobi, Kenya. Geoforum 59 (February), 228-39.

Toyama, K. (2010) Human-computer interaction and global development. Foundations and Trends ${ }^{\circledR}$ in HumanComputer Interaction 4.1, 1-79.

UN-HABITAT (2008) State of the world's cities 2010/2011: bridging the urban divide. Report. Earthscan, London.

UN-HABITAT (2010) The state of African cities 2010: governance, inequalities and urban land markets. Report. UN-HABITAT, Nairobi.

UN-HABITAT (2014) The state of African cities 2014: re-imagining sustainable urban transitions. Report. UN-HABITAT, Nairobi.

Waema, T., C. Adeya and M. Nyambura Ndung'u (2010) Kenya ICT sector performance review 2009/2010: towards evidence-based ICT policy and regulation. Policy Paper 10.2, Research ICT Africa Network, Nairobi.

Wa Mungai, M. and D.A. Samper (2006) 'No mercy, no remorse': personal experience narratives about public passenger transportation in Nairobi, Kenya. Africa Today 52.3, 51-81.

Wilson, D. and R. Keil (2008) The real creative class. Social \& Cultural Geography 9.8, 841-47.

World Bank (2007) Citizen's report card on urban water, sanitation and solid waste services in Kenya: summary of results from Nairobi, Kisumu and Mombasa. World Bank, Washington, DC.

Wyche, S.P., T.N. Smyth, M. Chetty, P.M. Aoki and R.E. Grinter (2010) Deliberate interactions: characterizing technology use in Nairobi, Kenya. Proceedings of the ACM SIGCHI Conference on Human Factors in Computing Systems (CHI 2010), Atlanta, GA, 10-15 April.

Yitamben, G. and E. Tchinda (2009) Internet use among women entrepreneurs in the textile sector in Douala, Cameroon: self-taught and independent. In I. Buskens and A. Webb (eds.), African women \& ICTs: investigating technology, gender and empowerment, UNISA Press, Pretoria. 